\title{
Politeness in Persian and English Dissertation Acknowledgments
}

\author{
Mohammad Javad Mohammadi \\ Fraydan Branch, Islamic Azad University, Isfahan, Iran \\ Bamshad Hekmatshoar Tabari \\ Shahid Chamran University of Ahvaz, Iran
}

\begin{abstract}
Though usually seen as just marginally related to the key academic goals of establishing claims and reputations, acknowledgement as a genre is widely employed in academic discourse to express gratitude for the contribution of an individual or an institution so that writers establish a favorable academic and social position. Having considered the significance of acknowledgment texts in academic writing and the fact that little, if any, has been devoted to highlight dissertation acknowledgments in the Iranian academic context, the current study, adopting Arundale's face theory, examined the politeness strategies of 70 doctoral dissertation acknowledgments written by native speakers of Persian (henceforth NSP) and native speakers of English (hereafter NSE) in 7 disciplines representing soft sciences. The findings revealed that approximately majority of communicative moves and linguistic steps exploited by the two groups function as connection face except for cases in which writers accept the responsibility of possible errors and weaknesses of the dissertation. Of course, Persian writers, due to their cultural background, used this step more than English ones. To sum up, the study provided valuable information about the socio-cultural practices and personal identity of the writer encoded in the organizational components of this type of genre.
\end{abstract}

Index Terms - cross-cultural, dissertation, acknowledgments, politeness, face

\section{INTRODUCTION}

Undoubtedly, writing a dissertation is a difficult task. It requires not only days and nights of allocated time of the writer, but also the assistance and encouragement of the other people, who will all be with him/her in both academic and moral realms. So, acknowledgments in dissertations, as argued by Hyland (2004), allow students to demonstrate their awareness of central academic values such as modesty and gratitude, establish their credibility, recognize debts, and achieve a sense of closure at the end of what is often a long and demanding research process (p. 304).

A dissertation acknowledgment, defined as a "Cinderella" genre (Hyland 2003, p. 243) which is "neither strictly academic nor entirely personal" seems to belong to the institutional group, however, constituting a peculiar genre of its own. The writers of these genres have attempted to produce texts that plausibly reflect interaction with different audiences in terms of exchange of materials, information, support, and advice. Taking genre analysis as the study of how language is used in a particular socio-cultural context, the attention of text analysts has therefore turned to examining the textual and generic organization components as well as the socio-cultural interactive features that writers draw on to engage their audience to establish and maintain a successful writer-reader relationship.

Acknowledgment as a genre is widely used in academic discourse to express gratitude toward help from and contribution of an individual or an institution, thus establishing a favorable academic and social reputation. Acknowledgments have been of some interest to genre analysts such as Giannoni (2002), Hyland (2003, 2004), and Hyland and Tse (2004).

The acknowledgment sections are, thus, short but important pieces of text. They orient the reader to what the student has done as well as where the student is placed in various scholarly and social networks. These seemingly simple texts need as much attention as other parts of student's text. Like the table of contents, the acknowledgment sections are often the last thing a student writes, but among the first things an examiner reads (Paltridge \& Starfield, 2007). As Finn (2005, p. 118) argues, "first impressions last" in the examination process. Clear and well-written acknowledgment sections can help make that first impression a good one.

Acknowledgment sections are now commonplace in academic books and research articles and appear to be almost universal in dissertations, where they offer students a unique rhetorical space to both convey their genuine gratitude for assistance and to promote a capable academic and social identity (Hyland \& Tse, 2004, p. 260).

On the other hand, the values and norms dominating cultures have attracted the attention of experts carrying out studies in social sciences, such as sociology, psychology, anthropology and inevitably studies in language which act as the primary tool for communication among people. To this end, it is not surprising to see that in recent years studies in social and interactional aspects of language have gained a significant attention and the number of studies has increased considerably. In this regard, as the studies have started to address specific cultures, it is revealed that the concept of 
appropriateness in language differs from culture to culture since different cultures are governed by some relatively different values and norms and these are reflected by different choices of language patterns in communication (Eisenstein \& Bodman, 1993; Koutlaki, 2002). Thus, considering the importance of acknowledgments which are sections read first by the ones who were with the $\mathrm{PhD}$ students throughout this difficult process and maybe by the ones wondering the academic and social network of the authors, the current study cross-culturally compares the doctoral dissertation acknowledgments written by NSP and NSE to unravel cultural differences in expressing gratitude across two languages.

\section{A. Research Questions}

The notion of politeness is shaped by different cultural perceptions. In different situations and contexts, politeness may be interpreted and evaluated differently in various cultures. Through the use of language, various aspects of the values and attitudes in a culture and the perception on politeness are manifested. Therefore, as an important consideration, this study will look into how two diverse cultures, Iranian and American, interpreting the notion of politeness in dissertation acknowledgment texts will be compared adopting Arundale's (2006) theory.

Drawing on the above-mentioned developments and tendencies in the field of linguistics, this study addresses the following questions:

1. In what ways are politeness strategies revealed in the doctoral dissertation acknowledgment texts written by Persian and English students?

2. Is there any difference in type and frequency of politeness strategies in Persian and English doctoral dissertation acknowledgment texts?

\section{B. Theoretical Framework}

Since 1980s, 'face', 'facework' and 'politeness' notions have been examined a lot by different scholars in the fields of pragmatics and sociolinguistics. To this aim, various types of theories concerning the imagined notions have been proposed which most of them were highly abstract directly or indirectly recourse to great variation of social strategies to construct co-operative social interaction across cultures.

A large number of theoretical and empirical books and articles concerning linguistic politeness and/or the notion of face and facework have been published in the last decades. In most of the studies, politeness has been conceptualized especially as strategic conflict-avoidance or as strategic construction of cooperative social interaction (cf. Eelen, 2001, p. 21; Watts, 2003, p. 47).

Politeness features in academic texts have been of growing interest among the experts in the field. There is a growing body of research that investigates the manifestation of politeness strategies in e-mail exchanges (e.g. Hartford \& Bardovi-Harlig, 1996; Biesenbach-lucas 2006, 2007; Chen, 2001, 2006; Crossouard \& Pryor, 2009; Vinagre, 2008), in computer-mediated discussion (e.g. Erika, 2010; Schallert, Cheng \& the D-Team, 2008; Schallert, Chiang, Park, Jordan, Haekyung, An-Chih, Hsiang-Ning, SoonAh, Taehee \& Kwangok, 2009), in prefaces (Meimei, 2001) and in research articles (Meldrum, 1994; Myers, 1989).

The most known theory of politeness, as asserted by many scholars, is Brown and Levinson's ground-breaking work (1978; reissued 1987). According to their seminal work, a speech is polite if one employ the kinds of verbal strategies which take the addressee's feelings into account by respecting his or her 'face' (Brown and Levinson, 1987, p. 61; Brown, 1998, p. 84). As argued by Goffman, face involves both the need/desire not to be imposed upon, i.e. negative face, and the need/desire to be liked or affirmed, i.e. positive face (Goffman, 1967, pp. 5-7). Thus, drawing on Goffman's theory, Brown and Levinson (1987) proposed that polite speech encompass all strategies addressing both types of needs.

Despite its merits, Brown \& Levinson's theory of politeness strategies has also been under severe dispute in the realm of research on politeness. It has been subject to some serious criticism calling it a more than enough pessimistic theory of social communication. Among the critics was Nwoye asserting that if we rely on Brown \& Levinson theory of politeness as a true one which holds that social interaction is an activity of continuous mutual monitoring of potential threats to the faces of the interactants, it could rob social interaction of all elements of pleasure (1992, p. 311). Werkhofer also criticized (1992, p. 156) Brown \& Levinson account of politeness as being essentially individualistic since it, at least during the production of speech, regards the speaker as a rational agent being unconstrained by social norms and thus, he/she is free to choose egocentric, asocial and aggressive intentions. According to Watt, the other major critique of Brown \& Levinson's model is freeing the speakers to select in the form of a decision-tree through which they have to work their way before they can arrive at the appropriate utterances in which to frame the FTA (2003, p. 88). This type of system excludes the possibility of happening two or more strategies at the same time.

An alternative, but complimentary, view of face that also addresses the criticisms of Brown and Levinson's theory examines positive and negative face as a relational rather than individual phenomenon (Arundale 1999, 2006; BargielaChiapini 2003). As one of the latest re-examinations of face as pertinent to politeness, Arundale (2006) which, contrary to the Brown and Levinson's (1987) politeness theory, examines positive and negative face as a relational rather than individual phenomenon. He argues that positive and negative faces are best addressed as the dialectical opposition between connection and separation from others: 
...connectedness and separateness provides a clear, culture-general conceptualization of "positive" and "negative" face.... As a re-conceptualization of positive face, "connection face" encompasses a range of interpretings much broader than, but inclusive of being "ratified, understood, approved of, liked or admired" by others (Brown and Levinson 1987 , p. 62). As a re-conceptualization of negative face, "separation face" encompasses meanings and actions that include among many others, a person's "freedom of action and freedom from imposition" or "claim to territories" (2006, pp. 204-205).

Thus, theoretically, the present study is based in politeness. The notion of "politeness" is a broad and complicated one with numerous theories and approaches, and it is socially determined. It is linked with social differentiations, with making appropriate choices which are not the same for all interlocutors and situations (Coulmas, 2005, p.86). Regarding the importance of politeness strategies in acknowledgment texts as one important part of academic writing and the fact that little attempt has been made to highlight how these strategies are incorporated into these texts, the current study also scrutinizes the politeness strategies in such texts. Thus, the study is revealing as it highlights certain rhetorical characteristics adopted by native writers across English and Persian.

\section{MEthodology}

\section{A. Corpus}

To conduct this study, two sets of data were collected for the study of dissertation acknowledgments. The first set includes 70 dissertation acknowledgments written by the NSE in soft sciences and the second set comprises 70 acknowledgments written by the NSP in the same realm of study. The reason for choosing soft sciences to be analyzed is the important role they play in human life. Social science or soft science studies the human aspects of the world. It includes an in-depth study and evaluation of human behavior by using scientific methods in either quantitative or qualitative manner. Consequently, seven disciplines of soft sciences namely literature, translation studies, applied linguistics, history, sociology, library sciences, and philosophy were selected and ten dissertation acknowledgments for each were studied across English and Persian.

\section{B. Procedures}

English data were gathered from the database of the Princeton University of America in New Jersey (including doctoral dissertations from different universities of America) as the representative sample of acknowledgments in dissertations written from 2005 to 2010. Selection of these texts was on the basis of their availability to the researcher, in the way that they were chosen and sent by a graduate from Princeton University who was informed of the purpose of the study and given adequate information about how to collect the data. For the Persian data, a series of trips was made to the universities of Ahvaz, Isfahan, Tabriz, Shiraz, Yasuj, Shahre-kord, and Mazandaran and samples of acknowledgments in dissertations written within the same time frame were picked from the relevant departments in the above mentioned universities once permission was made from the universities. The disciplines were then coded as Lit representing literature, Tra representing translation studies, Apl representing applied linguistics, His representing history, Soc representing sociology, Lib representing library sciences, and Phil representing philosophy. Also, in the current study, P stands for Persian, E stands for English, and ACK stands for acknowledgments.

\section{Data Analysis}

The principal procedure for analyzing the data in this study was comparative. The politeness strategies of the acknowledgment texts written in both languages were compared to see if they follow the same pattern. Frequency of each strategy was calculated and Cramer test was run to see whether possible differences were statistically significant. In the next stage, qualitative and quantitative analyses provided richer and deeper insight into the nature and function of each move.

\section{RESUltS AND Discussions}

Thus, drawing on the face model proposed by Arundale (2006), the current study compared dissertation acknowledgments written by NSP and NSE in terms of politeness strategies both qualitatively and quantitatively. The results revealed that connection face is the dominant one with about $88 \%$ occurrence in both languages and separation face only occurred in less than $12 \%$ of all texts (Table 1 ).

TABLE1.

FREQUENCY OF FACES IN PERSIAN AND ENGLISH ACKNOWLEDGMENTS

\begin{tabular}{|l|l|l|}
\hline & Persian (\%) & English (\%) \\
\hline Connection & $227(84)$ & $208(95)$ \\
\hline Separation & $43(16)$ & $10(5)$ \\
\hline
\end{tabular}

Following Arundale's (2006) model, all moves and steps, except shouldering responsibility sub-move, employed in these texts function as connection face as all are meanings apparent as unity, interdependence, solidarity, association, congruence, and more, between the writers and their relational partners. Our calculations revealed that this step has 
occurred in $84 \%$ of the Persian sample and more than $95 \%$ of the English sample. Here, two examples, one from Persian and one from English sample texts are given to clarify this sub-step.

1) Dâr payan bayâd sepas-e fâravan-e khod ra be hâmsar-e ba vâfayam tâghdim konâm ke dâr tey-e dore-e tâhsilatâm dâr karshenasi-e ârshâd vâ doktora, doshvarihay-e ziadi ra tâhâmmol nemud. Payan name-e doktoray-e khod ra be ou tâghdim mikonâm. (P. ACK. Lit. No.3)

(Finally, I must dedicate my numerous thanks to my loyal wife who tolerated the years of difficulty during my MA and PhD education. I dedicate my dissertation to her)

2) I owe my special thanks to my family who endured this long process. My parents a have been helpful in spending a long time with grandchildren so I could accomplish my dissertation. (E. ACK. APL. NO. 6)

The calculated value of Cramer-test in this step revealed to be 0.210 ( $\mathrm{sig}<0.05$ ), illustrating no statistically significant difference between the two groups. Most of the sentences and phrases applied in acknowledgment texts function as connection face as the main motivation behind writing this genre, as held by AL-Ali (2010), is to produce texts that plausibly reflect interaction with different audiences in terms of exchange of materials, information, support, and advice (p. 2). As the above examples suggest, the aim of the writers is to express relational connection. For instance, as the first example reveals, the writer tries to show the congruence between and make a powerful association with his wife and himself by first describing the difficulties they had to endure and then dedicating the dissertation to her to be thankful for her tolerance. Or as the second example suggests, the writer tends to reveal the interdependence and unity between his family members, most notably his parents with first expressing gratitude, then delineating the difficulties they have experienced during the long journey of writing dissertation.

Separation occurred in more than $16 \%$ of the Persian and less than 5\% of the English acknowledgements analyzed. Our analysis disclosed that all sentences and phrases utilized in the shouldering responsibility step function as separation since the writer tries to exempt academic characters from the possible errors of the dissertation. In other words, here, the writer wants to exonerate his instructors from the weaknesses and deficiencies of the dissertation and attribute them to his knowledge disabilities and by this the writer shows the dissociation and divergence between his instructors and himself as well as his autonomy in committing possible errors. Note the following examples, one from Persian and one from English sample texts.

3) Dar payan motazakker mishavam ke bandeh masule kastiha, navaghes va zafhay-e an mibasham. (P. ACK. Soc. No. 4)

(Finally, it should be mentioned that I am the responsible for any inadequacies, faults and weaknesses of it.)

4) Weak points of the present work must be attributed to my knowledge limitations. (E. ACK. His. No. 6)

The Cramer-test revealed to be 0.003 ( $\mathrm{sig}<0.05$ ), showing a statistically significant difference in applying separation face. Attributing goofs to oneself to achieve face in the sense of relational separation can be justified by reference to the "Shekaste-nafsi "schema. "Shekaste-nafsi" can be a subcategory to the cultural schema of Adab (politeness/respect) in Persian (Sharifian, 2008, cited in Shirinbakhsh \& Eslami Rasekh, 2012, p. 3). Since Persian is a language of Adab (politeness/respect), one may draw upon the schema of "Shekaste-nafsi" to gently evade compliment, so that it does not make the listener feel inferior and also it does not make the speaker feel arrogant. In fact, it is used in line with the policy of "self-lowering and other-raising" (Beeman, 2001, p. 41) which is counted as the manifestation of Adab (politeness/respect) in speech among Persians.

\section{CONCLUSION}

This study revealed that though the academic rules, regulations and conventions might constrain writers' choice of thanking expressions to more uniform forms of thanking across cultures (Al-Ali, 2010; Hyland, 2003; Hyland, 2004), the social and cultural background of writers still have an effect on their language choices (Hatipoğlu, 2009). In the way that, there were both matches and mismatches between the two languages in terms of exploiting different politeness strategies adopting the face model proposed by Arundale (2006) in which communication is interpreted considering connectedness with others as well as by separateness from them. Arundale's approach to face provides a culture-general conceptualization that can be adapted to the analysis of written discourse in a variety of cultures and settings.

Cross-cultural differences in the employment of certain strategies in certain speech acts have been widely discussed in the literature of language studies such as pragmatics, sociolinguistics, and second/ foreign language teaching (e.g., Eisenstein \& Bodman, 1993; Hatipoglu, 2009; Ohashi, 2008; Ruhi, 2006; Yu, 2003). In majority of the studies, it is discovered that the socio-cultural and/ or situational factors have great influence on the choice of language forms while performing some language acts. Stated differently, the choice of speech act patterns shows variation across cultures since language forms function differently in different cultures. As a matter of fact, language is a phenomenon which can hardly be viewed separate from its very inherent component, culture. This component does by all means play a significant role in enabling the language to gain a global status. 


\section{REFERENCES}

[1] Al-Ali, M.N. (2010). Generic patterns and socio-cultural resources in acknowledgments accompanying Arabic PhD dissertations. Pragmatics, 20 (1), $1-26$.

[2] Arundale, R. B. (1999). An alternative model and ideology of communication for an alternative to politeness theory. Pragmatics, 9 (1), 119-154.

[3] Arundale, R. B. (2006). Face as relational and interactional: A communication framework for research in face, facework, and politeness. Journal of Politeness Research, 2, 193-216.

[4] Bargiela-Chiappini, F. (2003). Face and politeness: new (insights) for old (concepts). Journal of Pragmatics, 35 (10-11), 14531469.

[5] Beeman, W. O. (2001). Emotion and sincerity in Persian discourse: Accomplishing the representation of inner states. International Journal of the Sociology of Language, 148, 31-57.

[6] Biesenbach-Lucas, S. (2006). Making requests in email: Do cyber-consultations entail directness? Toward conventions in a new medium. In K. Bardovi-Harlig, J. C. Félix-Brasdefer \& A. Omar (Eds.), Pragmatics and language learning (pp. 81-108). Honolulu, HI: Second Language Teaching and Curriculum Center, University of Hawaii.

[7] Biesenbach-Lucas, S. (2007). Students writing emails to faculty: An examination of e-politeness among native and non-native speakers of English. Language Learning \& Technology, 11 (2), 59-81.

[8] Brown, P., \& Levinson, S. (1978). Universals of language use: Politeness phenomena. In E. Goody (Eds.), Questions and politeness (pp. 56-324). Cambridge: Cambridge University Press.

[9] Brown, P., \& Levinson, S. (1987). Politeness: Some universals in language use. Cambridge: Cambridge University press

[10] Chen, C-F. E. (2001). Making e-mail requests to professors: Taiwanese vs. American students. Paper presented at the Annual Meeting of the American Association for Applied Linguistics, St. Louis, MO, America.

[11] Chen, C-F. E. (2006). The development of e-mail literacy: From writing to peers to writing to authority figures. Language Learning \& Technology, 10 (2), 35-55.

[12] Coulmas, F. (2005). Sociolinguistics: The study of speaker's choice. Cambridge: Cambridge University Press.

[13] Crossouard, B., \& Pryor, J. (2009). Using email for formative assessment with professional doctorate students. Assessment \& Evaluation in Higher Education, 34, 377-388.

[14] Eelen, G. (2001). A critique of politeness theories. Manchester: St. Jerome.

[15] Eisenstein, M., Bodman, J. (1993). Expressing gratitude in American English. In Kasper, G., Blum-Kulka, S. (Eds.), Interlanguage Pragmatics (pp. 64 - 81). New York: Oxford University Press.

[16] Erika, D. (2010). Politeness in computer-mediated discourse of a virtual team. Journal of Politeness Research. Language, Behaviour, Culture, 6 (1), 129- 150.

[17] Finn, J.A. (2005). Getting a PhD: An action plan to help manage your research, your supervisor and your project. London: Routledge.

[18] Giannoni, D. S. (2002). Worlds of gratitude: A contrastive study of acknowledgment texts in English and Italian research articles. Applied Linguistics, 23, 1-31.

[19] Goffman, E. (1955). 'On face-work: An analysis of ritual elements in social interaction'. Psychiatry: Journal of Interpersonal Relations, 18, 213-231. Reprinted in: E. Goffman (1967) Interaction Ritual. Chicago: Aldine Publishing, 5-46.

[20] Hartford, B. \& Bardovi-Harlig, K. (1996). "At your earliest convenience": A study of written student requests to faculty. In L. F. Bouton (Eds.), Pragmatics and language learning (pp. 55-69). Urbana, IL: DEIL.

[21] Hatipoğlu, Ç. (2009). Culture, gender, and politeness: Apologies in Turkish and British English. Saarbrücken: VDM Verlag Dr. Mull Aktiengesellschaft \&Co. KG.

[22] Hyland, K. (2003). Dissertation acknowledgements: The anatomy of a Cinderella genre. Written Communication, 20, $242-268$.

[23] Hyland, K. (2004). Graduates' gratitude: The generic structure of dissertation acknowledgements. English for Specific Purposes, 23, 303-324.

[24] Hyland, K., \& Tse, P. (2004). "I would like to thank my supervisor": Acknowledgements in graduate dissertations. Applied Linguistics, 14, 259-275.

[25] Koutlaki, S. A. (2002). Offers and expressions of thanks as face enhancing acts: Ta' arof in Persian. Journal of Pragmatics, 34, $1733-1756$

[26] Meimei. (2001). A contrastive Study of Politeness Strategies in Chinese and English Prefaces. Unpublished dissertation, Zhejiang Normal University

[27] Meldrum, G. (1994). The Politeness of Criticism in Applied Linguistics Articles: Readership and Aspects of Aggravation. Unpublished MA Dissertation in Applied Linguistics. University of Sheffield.

[28] Myers, G. (1989). The Pragmatics of Politeness in Scientific Articles. Applied Linguistics, 10 (1), 1-35.

[29] Nwoye, Onuigbo G. (1992) Linguistic politeness and socio-cultural variations of the notion of face. Journal of Pragmatics 18 , 309-328.

[30] Ohashi, J. (2008). Linguistic rituals in Japanese thanking: Balancing obligations. Journal of Pragmatics, 40, 2150 - 2174.

[31] Paltridge, B., \& Starfield, S. (2007). Thesis and dissertation writing in a second language: a handbook for supervisors. New York, NY: Routledge.

[32] Ruhi, Ş. (2006). Politeness in compliment responses: A perspective from naturally occurring exchanges in Turkish. Pragmatics, $16(1), 43-101$.

[33] Schallert, D. L., Cheng, A., \& the D-Team (2008). Politeness and perceptions of politeness: How face saving strategies mediate computer-mediated classroom discussion. Paper presented at the annual conference of the American educational research association, New York.

[34] Schallert, D. L., Chiang, Y.V., Park, Y., Jordan, M.E., Haekyung. L., An-Chih, C., Hsiang-Ning, R. C., SoonAh, L., Taehee, K., $\&$ Kwangok, S. (2009). Being polite while fulfilling different discourse functions in online classroom discussions. Computers \& Education, 53 (3), 713-725 
[35] Shirinbakhsh, S., \& Eslami Rasekh, A. (2012). The effect of age on cultural schema: The case of Shekaste-nafsi (modesty) in Persian. International Journal of Research Studies in Language Learning, 1 (1), 1-14.

[36] Vinagre, M. (2008). Politeness strategies in collaborative e-mail exchanges. Computers \& Education, 50, $1022-1036$.

[37] Watts, R. (2003). Politeness. Cambridge: Cambridge University Press.

[38] Werkhofer, K. T. (1992). Traditional and modern views: The social constitution and the power of politeness. In R. J. Watts, S. Ide, \& K. Ehlich, (Eds.), Politeness in language: studies in its history, theory and practice (pp. 155-197). Berlin: Mouton de Gruyter.

[39] Yu, M. (2003). On the universality of face: evidence from Chinese Complement response behavior. Journal of Pragmatics, 35, $1679-1710$.

Mohammad Javad Mohammadi is an MA in TEFL from Shahid Chamran University of Ahvaz. His line of interest includes Contrastive Analysis, Discourse Analysis, and Language Testing. He has published some articles in national and international journals. He also has presented in some international conferences. He is currently teaching different English courses at Isla mic Azad University of Fraydan.

Bamshad Hekmatshoar Tabari is an MA in English Literature from Shahid Chamran University of Ahvaz. His line of interest includes Discourse Analysis, Literary criticism and Literature teaching. He has published some articles in national and international journals. He also has presented in some international conferences. He is currently teaching different English courses at language institutes. 